\title{
Ética y Sinsentido. Kierkegaard y Wittgenstein
}

\author{
Patricia C. Dip \\ (Universidad de Buenos Aires, CONICET)
}

\begin{abstract}
Even though there are coincidences between Kierkegaard and Wittgenstein's ideas towards ethics, their projects are not identical. The main purpose of this article is to highlight that Kierkegaard's conception of ethics has nothing to do with the early Wittgenstein's understanding of it. While in the Tractatus it is not possible to develop any "ethical theory", Kierkegaard allows us to discuss from an ethical point of view. Therefore, the relationship between indirect communication and the notion of "showing" does not represent an identity.
\end{abstract}

\section{Introducción}

Aun cuando Kierkegaard y Wittgenstein provienen de tradiciones filosóficas distintas, pueden hallarse puntos de contacto entre las ideas que elaboran en torno a la cuestión moral. La delimitación del problema ético realizada por ambos pensadores puede comprenderse si se tiene in mente el origen común del planteo, es decir, la epistemología de Kant. Tanto Kierkegaard como Wittgenstein parten de la distinción kantiana entre razón teórica y razón práctica, aceptando por tanto la diferencia entre el mundo de los hechos y el de los valores expresada por la dialéctica ser-deber ser, que supone mantener separados los planos de la ética y la ontología.

Sin embargo, no adhieren al proyecto ético del filósofo alemán pues ninguno de ellos concibe la ética en el contexto de un plan "sistemático" haciendo hincapié en la incapacidad de la ciencia para dar cuenta apropiadamente del problema ético. Por otra parte, en el caso del danés, si fuera posible discutir la posibilidad de encontrar el fundamento último de la moral, jamás lo haría sobre la base del 
supuesto de la autonomía de la razón, pues el punto ciego de su reflexión es el cristianismo y el sentido cabal de lo ético es presentado a partir del presupuesto religioso que convierte a la autonomía en un mero espejismo. En este punto, la diferencia con el primer Wittgenstein es radical puesto que el vienés no hace uso de ningún presupuesto dogmático.

La idea primordial de este artículo consiste en señalar que, si bien ambos pensadores parten del mismo presupuesto metodológico de raigambre kantiana, que los obliga a distinguir el discurso ético del científico, las consecuencias que derivan de ello son distintas. Mientras el primer Wittgenstein rechaza la posibilidad de decir algo significativo sobre la ética aun cuando reconoce su valor absoluto, Kierkegaard intenta hacerlo siguiendo un camino indirecto puesto que el sentido último del bien y el mal no puede ser "conocido" cuando se supone que la ética descansa en presupuestos de orden teológico que exigen reconocer los límites de la humana razón para dar paso a la revelación divina, origen último e indescriptible de los fenómenos cristianos.

\section{El problema del sentido}

Es posible abordar un libro polémico y ambiguo como el Tractatus tomando como pivote el problema del "sentido". Pensado de esta manera, el intento de Wittgenstein no consiste en la formulación de una teoría del conocimiento sino en la discusión de las condiciones de posibilidad de cualquier discurso "significativo". El trabajo de Wittgesntein es preliminar, anterior a la discusión epistemológica misma. No obstante, el modelo que sigue para poder establecer las condiciones que debe cumplir el discurso con sentido proviene de la epistemología kantiana. La idea de "critica" le otorga a Wittgenstein la herramienta fundamental para determinar el "limite" entre lo pensable y lo impensable. ${ }^{1}$ El limite de la razón debe establecerse

\footnotetext{
1 "El limite del lenguaje se revela en la imposibilidad de describir el hecho que corresponde a una frase (que es su traducción), sin repetir justo esta frase. (Aqui tenemos que ver con la solución kantiana del problema de la filosofia)". Ludwig WitTGenstein: Cultura y Valor, trad. Elsa Cecilia Frost, Madrid: Espasa Calpe, S.A. 1995 , p. 45.
} 
desde adentro, pues de lo contrario, se permite que su uso se extienda de manera inadecuada. ¿Qué oficia de limite? El sentido. Asumiendo una relación isomórfica entre pensamiento y lenguaje, lo pensable es lo que puede "decirse" en el lenguaje de manera significativa.

Aceptando que una de las acepciones del "sinsentido" (Unsinning) refiere a lo que Wittgenstein llama "lo más alto", la pregunta que surge es si es posible o no acceder de alguna manera significativa a lo místico, cuando en sentido estricto, ha sido relegado a la esfera de lo "incomunicable". ¿Es posible realizar un tránsito de lo incomunicable a lo comunicable en el contexto del Tractatus? Es decir, ¿es posible otorgarle algún tipo de "sentido" al sinsentido? James Conant, Cora Diamond, y Jaime Ferreira responden de modo negativo a este interrogante. La idea es que no es posible distinguir entre dos tipos distintos de "sinsentido", uno mero sinsentido y otro un sinsentido cognitivamente significativo. De este modo, lo que se intenta evitar es que haya alguna manera de acceder al reino mistico de las "verdades inexpresables". Ni la ética ni la filosofia ni la lógica pueden ser descriptas por proposiciones significativas y caen indefectiblemente en el terreno del "pleno sinsentido". Si bien comparto esta idea y considero que es pertinente pensar el Tractatus como una obra que se "auto elimina", con lo cual acepto la postura de Diamond ${ }^{2}$ que induce a tomar literalmente la sugerencia del propio Wittgenstein de "tirar la escalera" una vez utilizada, creo que tanto Conant ${ }^{3}$ como Ferreira ${ }^{4}$ van demasiado lejos cuando intentan comprender a Kierkegaard utilizando el mismo modelo explicativo. Si bien es posible pensar la distinción kierkegaardiana entre discurso directo y discurso indirecto como una analogia de la diferencia entre

2 Cora Diamond: "Throwing Away the Ladder", Philosophy, The Joumal of the Royal Institute of Philosophy Published by Cambridge University Press LXIII-243 (1988), pp. 5-27.

3 James Conant: "Kierkegaard, Wittgenstein, and Nonsense", en Pursuits of Reason, Essays in Honor of Stanley Cavell, edited by Ted COHEN, Paul GUYER, and Hilary PutnaM, Texas: Texas Tech University Press 1993, pp. 195-224.

${ }^{4} \mathrm{M}$. Jamie FerreirA: "The Point Outside the World: Kierkegaard and Wittgenstein on Nonsense, Paradox and Religion", en Religious Studies, 30, Cambridge: Cambridge University Press 1994, pp. 29-44. 
"decir" y "mostrar", esto sólo puede hacerse en un plano superficial de análisis. Pues, aunque en el caso de Wittgenstein no hay ninguna idea sustantiva de "lo ético", no sucede lo mismo en el caso de Kierkegaard, que si bien plantea la comunicación de lo ético como una dificultad, no lo hace porque no haya "nada que decir" sino por el carácter paradójico mismo del objeto del que intenta dar cuenta con la producción de la "primera autoría", "Det ethiske" (lo ético).

Al partir de la teoría figurativa del lenguaje, lo que define el sentido para Wittgenstein es la posibilidad de "representar" la realidad. Esta representación en sí misma puede ser evaluada con un criterio de verdad bivalente. La proposición que no representa la realidad de manera adecuada no es, por lo tanto, un sinsentido, sino que es sencillamente "falsa". La proposición que no tiene sentido es la que no permite ser contrastada por medio de este criterio de verdad.

Para que la proposición pueda referirse representativamente a la realidad tiene que compartir con ella la forma lógica, debe haber un "isomorfismo" entre las dos instancias que posibilite que una se convierta en " re-presentante" y la otra en "re-presentado". La proposición, justamente, re-presenta, es decir, vuelve presente lo que ya está presentado en la realidad misma. Jamás podría realizar esta tarea de manera exitosa si no se supusiera una identidad estructural, que es lo que Wittgenstein llama "forma de figuración". El elemento común que posibilita la identidad entre lenguaje y realidad sobre la cual se construye la representación es de naturaleza "lógica". Wittgenstein no asume con esta teoría compromisos ontológicos. No define ni la naturaleza ni la esencia de la realidad. Su labor no es metafisica ni epistemológica. No nos dice ni qué es la realidad ni cómo conocerla. Su trabajo preliminar, en todo caso, intenta pensar los presupuestos que toda metafísica y toda epistemología deberían tomar como punto de partida. Es decir, antes de determinar qué es lo real, y antes de formular un modo de acceso epistemológico a la realidad debo preguntarme por el medio que utilizo para definir estos problemas, el lenguaje. 
El fundamento del lenguaje significativo en general, dentro del cual habria que incluir el lenguaje matemático, es lógico. Por eso la lógica es trascendental, en el sentido de ser la que determina las condiciones de posibilidad del lenguaje en general. La diferencia con Kant en este punto es que Wittgenstein no está preguntando por las condiciones de posibilidad de la objetividad en general pues su concepción de "representación"critica el modelo kantiano, dado que distingue entre sentido y realidad. No hay función sintética del sujeto trascendental que permita que el modo de acceso a la realidad dependa de la constitución mental del sujeto. 0 , en otras palabras, que exija que la realidad se defina en términos de identidad con el sujeto que la piensa. ${ }^{5}$

En este contexto, los hechos que acaecen en el mundo no responden, como en Kant, a la ley de causalidad. Por lo tanto, el sucederse o no sucederse de los mismos es meramente "accidental". No hay ninguna necesidad metafisica que exija que, a partir del establecimiento de una o más causas, deba seguirse ningún efecto con necesidad. No hay nada del orden de lo necesario en la realidad. La sugerencia de Wittgenstein, es justamente, que la búsqueda de cualquier sentido de la realidad que se vincule con la idea de "necesidad" o implique comprender el mundo de manera no relativa o accidental, debe orientarse hacia lo que está "fuera" del mundo como "todo limitado". Esta búsqueda misma supone el "traspasar" los límites del mundo. Hace referencia al inevitable intento de trascender el sentido fáctico en búsqueda del sentido no accidental o absoluto del que se hace mención en la Conferencia de ética. En el Tractatus, Wittgenstein establece con precisión los limites de esta búsqueda. Que exista una natural tendencia humana a traspasar los límites del sentido, no significa que esta tendencia esté justificada y mucho menos que la región místico-ética pueda volverse transparente para el lenguaje proposicional. No hay identidad posible entre la realidad no factual y el lenguaje en los términos representativos en los que éste es comprendido en el Tractatus. En

${ }^{5}$ Desde este punto de vista, el Tractatus puede concebirse como un intento de pensar la noción de representación a partir de la crítica a la metafísica moderna, basada en la idea cartesiana de ego cogito. 
todo caso, la ética queda relegada a la región mística pues se refiere al "Sinn der Welt" y este escapa los límites de la teoría representativa del lenguaje. No puede ser dicho con sentido y por lo tanto todo intento de volverlo "decible" implica la ruptura de la identidad isomórfica establecida entre los hechos del mundo y las proposiciones que los expresan. Para el primer Wittgenstein, decir algo con sentido sobre la ética supone el abandono de su propia teoría representativa. En el contexto del Tractatus no es posible hacerlo. De ética no se puede hablar y cualquier intento de hablar de ética está condenado al fracaso del "sinsentido". La posibilidad de construir un discurso significativo sobre la ética implica o bien abandonar el Tractatus o bien "callar".

Ahora bien, dentro del contexto explicativo de la obra de Wittgenstein el "silencio" mismo se vuelve problemático. Callar no quiere decir necesariamente que no haya nada que decir al respecto de lo ético como puede suponerse desde un punto de vista positivista. La paradoja, sin embargo, está siempre latente pues, todo lo que se diga, será inevitablemente un "sinsentido". Kierkegaard tiene un lugar importante que ocupar en este juego pues también supone que la naturaleza misma de lo ético exige el "silencio" en búsqueda de un modo más radical de expresión de lo moral en la "actualidad" de la propia existencia. Si la ética tiene, efectivamente, el valor absoluto que Wittgenstein parece otorgarle, entonces no puede hacerse referencia a ella de manera relativa. Toda referencia a la misma en el contexto proposicional no puede pensarse más que como una forma de "reduccionismo".

\section{Decir y Mostrar}

James C. Edwards 6 sostiene que el concepto de "mostración" intenta salvar a la ética y la lógica de la encrucijada en la que las coloca la teoría pictórica del lenguaje, a saber: el "sinsentido". Si bien el primer Wittgenstein adhiere aún a algunas premisas de la idea "representacionista" del conocimiento, no concibe la representación

\footnotetext{
${ }^{6}$ James C. EDWARDs: Ethics without Philosophy. Wittgenstein and the Moral Life.
} Florida: University Presses of Florida 1985. 
como "fundamento último" y de ese modo abre un abismo entre voluntad y pensamiento. La voluntad no es "razón práctica" y no es posible dar cuenta de ella en términos racionales. El pensamiento se reduce a la descripción del mundo de los hechos y no ocupa ningún lugar prescriptivo. Otorgarle al mundo "valor" es un acto subjetivo de la voluntad que no puede presentar ninguna pretensión de verdad. La valoración no se refiere al mundo desde.el punto de vista del sujeto que describe los hechos que en él acaecen sino que hace referencia al mundo como "totalidad", noción que, en sentido estricto, hace imposible la teoria representativa del lenguaje pues ésta no puede describir la totalidad, ya que es esta misma totalidad la que se constituye en su límite y en la condición de posibilidad de la descripción. Para poder describir el mundo como un "todo" el sujeto debería ser el sujeto absoluto o total, debería poder comprender los hechos del mundo desde un punto de vista que elimina la noción misma de "hecho". El sujeto debería ser Dios.

La imposibilidad de describir el mundo como un todo limitado, es decir, la imposibilidad para, desde el punto de vista - siempre limitado - del sujeto poder "ver" y "representar" el mundo desde "fuera" del mundo, genera la noción misma de "mostración". No es posible describir el mundo desde "fuera" del mundo. No se puede "conocer" lo que está más allá de los límites del lenguaje, pues para poder realizar tal actividad habria que utilizar un lenguaje "b" que diera cuenta del "lenguaje a" y asi ad infinitum. Wittgenstein quiere evitar esta progresión al infinito estableciendo una "reductio" que, comprendida en sentido estricto, reduce el problema del "sentido del mundo" al silencio.

La noción de "mostración" sólo puede comprenderse como opuesta dialécticamente a la idea de "decir". Ahora bien, ¿cuál es el valor "explicativo" que tiene esta idea? En sentido estricto, deberiamos decir que su valor explicativo es "eliminativo" en tanto y en cuanto elimina el contexto mismo de la explicación en términos de "decir". ¿Puede "mostrarse" el limite del mundo y el pensamiento"? Si, lo místico muestra ese limite, y al hacerlo condena al sinsentido todo intento de explicar en términos "positivos" el contenido de la mostración. Aquello que es objeto de la teoría de la 
"mostración" no puede tener contenido alguno, puesto que si lo tuviera debería poder "decirse".

Lo que se muestra no puede ser "traducido" a ninguna forma de "decir" pues este supuesto conduce al cuestionamiento de la idea central de la teoría pictórico-representativa del lenguaje, es decir: la noción de límite. Si estos dos términos tienen algún medio de volverse transparentes uno frente al otro, si se plantea cualquier forma de identificación entre decir y mostrar entonces no hay nada de lo que no se puede hablar. Si se pudiera hablar de todo, el decir se convertiría en a-significativo. Decir una proposición con sentido en el contexto del Tractatus depende de la postulación misma de la noción de "sinsentido", que funciona como "limite". Si puedo decir la totalidad, si es posible concebir el mundo como "todo limitado", no hay diferencia alguna entre voluntad y entendimiento. La tesis de la indistinción de estas dos facultades puede sostenerse sólo en el caso de Dios.

La diferencia entre las nociones de voluntad y entendimiento es el fundamento de la ética. El problema ético consiste justamente en hallar un modo de conciliar el pensamiento y la acción. La solución kantiana radica en concebir la voluntad misma como razón practica. Sin embargo, Wittgenstein rechaza esta solución y ese rechazo lo conduce a la imposibilidad de formular una teoria ética.

A pesar de que lo ético represente un problema importante en el pensamiento y la vida de Wittgenstein, el modo en el que lo contempla lo conduce a la negación del sentido de la ética. Su obra temprana lo convierte en el fundador de la "ética negativa". El resultado de ello es que comunica indirectamente que no hay ninguna manera positiva de acceder a lo ético. Que lo haga indirectamente depende de su noción "representativa" del lenguaje. No obstante, comunicar indirectamente no significa que haya un "algo" positivo que decir. La diferencia con Kierkegaard radica en que este último desea, a pesar de comprender la contradicción implícita que ello supone, comunicar algo positivo, o en otros términos, sustantivar la ética. 
Desde el punto de vista del Tractatus, Kierkegaard comprende el problema de lo ético de manera "reduccionista". Mientras el primer Wittgenstein no propone ninguna instancia de "reconciliación" o recuperación del sentido perdido, Kierkegaard intenta recuperar el sentido de lo ético a través de la incorporación de categorias religiosas. De este modo, la ausencia de contenido positivo que tiene necesariamente la ética en el primer Wittgenstein, es reemplazada por la posibilidad de recuperación del pleno sentido. La paradoja kierkegaardiana es la plenificación del sentido de lo ético. Exige al mismo tiempo la eliminación y la recuperación en permanente tensión y Abraham es el modelo paradigmático de esta recuperación. La razón debe ser abandonada, pues colisiona, choca contra su propio límite. Sin embargo, ninguna plenificación es posible si la razón no es al mismo tiempo recuperada. ${ }^{7}$ La paradoja, la existencia del Dios-hombre, la aparición de Dios en el tiempo es la condición de posibilidad de lo ético en Kierkegaard.

\section{El "dilema" de la comunicación de det ethiske (lo ético)}

El dilema de "lo ético" radica en el intento de convertirlo en objeto de "comunicación", pues en sentido estricto la ética es "incomunicable". Esto es algo que Kierkegaard vio muy claramente y por eso no es casual que un pensador extremadamente cuidadoso al

${ }^{7}$ El problema radica en que, según Temor y Temblor, el único modo de recuperar la razón es a través de "la suspensión teleológica de la ética" y Johannes de Silentio no explicita de qué modo puede la ética ser conservada en una esfera superior una vez que su pertinencia ha quedado "suspendida". La ética no puede ser abandonada bajo ningún respecto y en ningún instante, pues de lo contrario no habría modo de evitar el irracionalismo. Abraham es cuestionado por el universal ético, "lo general", puesto que intenta realizar una acción que la ética sólo puede calificar como "asesinato". El recurso que se utiliza en la obra para justificar la decisión del padre de la fe consiste en especificar la particularidad absoluta del individuo religioso que, en su carácter de tal, pasa por encima del estadio ético en su conjunto para establecer una relación absoluta con lo absoluto, relativizando de esta manera las exigencias mismas de la ética. En el caso de Abraham, quien escapa por completo a la mediación, la ética y por consiguiente la racionalidad, quedan "suspendidas" teleológicamente en una esfera superior, exigiendo la introducción de una nueva categoria para comprenderlo, la religiosa. 
respecto de los detalles más sutiles de la publicación de su obra, trate el tema de la "comunicación" de lo ético en un texto que, en primer lugar, intentaba ser la base para el dictado de unas Conferencias ${ }^{8}$ (Papirer VIII 2 B) que no resultaron pronunciadas, y en segundo lugar, jamás fuera publicado durante su vida. Creo que este proceder forma parte de la "estrategia" indirecta de comunicación de lo ético, cuyo medio más apropiado de expresión resulta ser la ironía. “Por qué utiliza el moralista la ironia como su incógnito? Porque él aprehende la contradicción que existe entre el modo en que existe interiormente y el hecho de no expresarlo exteriormente". 9

En las Conferencias parece quedar claro que, si bien Kierkegaard es concebido generalmente como un pensador religioso, su preocupación primigenia es de carácter ético. Aquí es pertinente introducir una distinción entre la ética como disciplina filosófica y el ámbito propio de lo normativo, por un lado, y lo que el danés denomina "lo ético", que hace referencia al interés (interesse) subjetivo. "Lo ético"10 es el medio que permite al individuo romper con la inmediatez indiferenciada del mundo estético a través de la reflexión. Jamás sería posible acceder a la "segunda inmediatez" de la esfera religiosa sin haber realizado previamente la "crítica" de la "primera inmediatez" de la esfera estética. En este sentido, si bien el telos de la filosofia de Kierkegaard está representado por la "segunda inmediatez", no es posible acceder a ella sin la anterior irrupción del

${ }^{8}$ Con el título de: "Den Ethiske og den ethiske-religieuse meddelelses dialektik" (1847), fueron publicadas póstumamente en el Diario (Papirer VIII 2 B 79, 81-89) tanto las Conferencias como las notas en torno a las mismas escritas por Kierkegaard. Cfr. Soren Kierkegaards Papirer, Bind VIII 2, Anden forogede Udgave ved Niels Thulstrup, Ottende Bind, Andet Halvind, Søren Kierkegaards Optegnelser fra 1847 24. Januar til 184515. Maj, Gruppe B og C, Gyldendal, København, 1968.

${ }^{9}$ Kierkegaard's Concluding Unscientific Postscript, translated from the Danish by David F. Swenson, completed after his death and provided with Introduction and Notes by Walter Lowrie, Princeton: Princeton University Press 1944, p. 450.

${ }^{10}$ La noción de "lo ético" que aparece fundamentalmente en las Conferencias y en el Postscriptum hace referencia a tres cuestiones: el sentido personal y subjetivo de la ética expresado por la categoría kierkegaardiana de "interés" por la existencia; la idea de realidad o actualidad en oposición a la idealidad del pensamiento; y en relación con esto último, la exigencia de realización en el ámbito de la praxis. 
"interés"que conlleva consigo "lo ético". La ruptura con la inmediatez que produce la reflexión supone la incorporación de dos categorías derivadas de la facultad de juzgar, esto es, establecer "diferencias": el lenguaje -que introduce la diferencia entre el ámbito propiamente humano y el animal-y la ética -que supone la diferencia entre el bien y el mal. Estas diferencias cobran sentido para Kierkegaard gracias a la utilización de un principio explicativo "espiritual" (Aand). Las categorias de la reflexión son de orden psiquico o intelectual (Sjal) y exigen un principio de orden superior que las contenga. En la antropologia de Kierkegaard el hombre no alcanza su completo desarrollo hasta que no es introducida la espiritualidad. La síntesis entre cuerpo y alma no da cuenta de la existencia de un "yo" - sujeto de la predicación tanto como sujeto moral responsable - hasta que no se relacione consigo misma como aparece en La enfermedad mortal. La "conciencia" de la relación que permite al hombre reconocer su "dependencia" de lo eterno y poder acceder a la fe, o rechazarla para convertirse en "desesperado", es de carácter espiritual.

Kierkegaard comienza la Primera Conferencia preguntándose por las condiciones de posibilidad del discurso ético. Reconoce que tomar lo ético como objeto de discurso supone una contradicción, pues en sentido estricto de la ética no se puede hablar, dado que lo que ésta exige es "realización" efectiva (actualidad) como lo indica el uso del término danés "Virkelighed" sinónimo del alemán "Wirklichkeit". "Actualidad es la reduplicación existencial de lo que se dice"." No obstante, podríamos decir que existe una natural tendencia humana -en sentido kantiano- a "hablar" de lo ético. Ahora bien, cuando esto sucede, se plantean las siguientes posibilidades: o bien se habla de la ética a partir de lo que Kierkegaard denomina "reduplicación", es decir, se es lo que se dice, existe identidad entre el ser y el discurso; o bien se habla de ella de modo "a-ético", no se expresa en la propia existencia lo que se "enuncia" discursivamente; o se la presenta "inmoralmente", no sólo no se expresa lo que se es, sino que se expresa todo lo contrario. Es decir, las relaciones entre ética y discurso que están en juego son las

11 "'Virkelighed' er den existentielle Reduplikation af det Sagte", VIII.2 B, 85, 16. 
siguientes: 1) ético: identidad entre discurso y $\operatorname{ser}^{12} 2$ 2) a-ético, no ético: no identidad entre discurso y ser; 3 ) inmoral: oposición entre discurso y ser. Estos tres modos de relación entre ética y discurso se construyen sobre la base del siguiente supuesto: la "identidad absoluta" entre discurso y ser no se expresa discursivamente sino existencialmente.

La predicación de existencia es un ejercicio apropiado para el discurso científico pero no para el discurso ético. Si este último intentara utilizar los recursos propios del pensamiento cientifico, como ha hecho la modernidad, entonces la consecuencia natural no podria ser otra que la que Kierkegaard denomina "deshonestidad". La estrategia que Kierkegaard encuentra para eludir la deshonestidad se basa en la construcción del "discurso indirecto". La misma comunicación de lo ético es entonces dilemática, es "doble reflexión". Por un lado, el sujeto moral debe expresar en su propia existencia lo que proclama discursivamente. $Y$, por el otro, el discurso ético debe dar cuenta "en si mismo" de la naturaleza dilemática del problema ético. ¿De qué manera? Por medio de la utilización de lo que Kierkegaard llama " discurso indirecto", que en sentido estricto, se ocupa solamente de la comunicación de lo ético. La comunicación de lo ético-religioso, por su parte, exige de la tensión que se obtiene al contrastar el discurso indirecto con el directo como queda indicado en los Papirer VIII. 2 B.

El tipo de conocimiento que lo ético implica para Kierkegaard no responde al ideal de unidad sistemática de la razón teórica y práctica bajo un único principio rector, por lo cual el método apropiado para la aprehensión de lo ético no es el trascendental sino el mayéutico. Por lo tanto, Kierkegaard se aleja de Kant para acercarse a Sócrates, pero en un contexto histórico traspasado por el mensaje cristiano. Después de la aparición del cristianismo en la historia, no es posible plantear un retorno a la inmediatez estética del paganismo. En todo caso, lo que puede hacerse es plantear el problema en los términos de

${ }^{12}$ Uno de los ejemplos que da Kierkegaard es el siguiente: predicar la pobreza desde el punto de vista de la "actualidad" supone que el predicador mismo es pobre (Papirer, VIII. 2 B, 85, 16). 
la llamada "segunda inmediatez", que consistiría en adoptar el método socrático de autoconocimiento y reexaminación teniendo al Dios-hombre in mente como paradigma o ideal.

Kierkegaard hace referencia al "método socrático" en la cristiandad, a través del uso de pseudónimos. Estos pseudónimos son capaces de decir "yo", algo que la época moderna no ha sabido hacer, al menos poéticamente. La ética no puede ser comunicada de otro modo que no sea por medio de esta metodología puesto que lo que ella implica supone una relación personal del individuo con el comunicador, que en sentido estricto no puede oficiar más que como ocasión para que el receptor sea capaz de descubrir su propio yo como objeto de reflexión moral. El error ha sido enseñar el cristianismo como conocimiento en lugar de hacerlo como capacidad.

El error fundamental de la edad moderna en cuestiones de ética consistió en abandonar el noble camino de Kant, cuya nobleza se basa en la diferenciación de dos categorías fundamentales para Kierkegaard, a saber, la posibilidad y la realidad. Los cien táleros posibles no son sinónimo de los cien táleros reales para Kant. La ciencia y la investigación cometieron dos errores elementales: en primer lugar, se volvieron fantásticas (phantastisk) y en segundo lugar, se transformaron en "conocimiento puro" (rene Viden) olvidándose de lo que significa "ser humano". La imposibilidad de aprehender el sentido genuino de lo ético es consecuencia directa de este olvido. La relación que establece la ética con el conocimiento abstracto es de indiferencia pues Kierkegaard supone que todo ser humano sin excepción está de hecho en posesión de lo ético. ${ }^{13}$ Este es el elemento universalista de lo ético subrayado en Las obras del amor para indicar que la precisa dimensión del problema moral no es metafisica, como pensó la ciencia moderna, sino antropológica. La confusión de la modernidad consistió justamente en haber comunicado lo ético como ciencia. De esa manera, la modernidad se transforma en deshonesta. La deshonestidad de la edad moderna

\footnotetext{
13 "Lo ético se relaciona con el conocimiento de modo indiferente, es decir, supone que todo ser humano lo conoce" (Papirer, VIII.2 B, 81, 5).
} 
consiste en la falta de ingenuidad, de primitivismo. Pues toda existencia primitiva contiene una "reexaminación" de lo que es universalmente humano. La falta de la cualidad de reexaminación y la aceptación automática de la costumbre y el hábito, que permiten que éstos sean suficientes, es "deshonestidad". Con relación a lo ético y lo ético-religioso, la comunicación genuina y la instrucción, es ejercitación (práctica). Si la edificación es comunicada como conocimiento, uno jamás recibe una edificación sino que está siempre recibiendo un saber. La diferencia entre edificación en lo ético y en lo ético-religioso es que lo ético es lo universalmente humano en sí mismo pero la edificación religiosa (cristiana) debe en primer lugar comunicar un conocimiento. Ahora bien, una vez que se ha cumplido con este requisito, se produce la misma relación que en lo ético. En el caso de la instrucción, la comunicación no debe ser como la de un conocimiento sino edificación práctica, instrucción artística.

La comunicación de lo ético supone sacar del individuo lo que ya está en él con anterioridad. El proceder de la modernidad, por el contrario, sólo se ocupa del pensamiento puro. ${ }^{14}$ De esta manera, "toda la ciencia moderna en torno a la ética es, éticamente entendida, un rodeo". ${ }^{15}$ La ausencia del problema de "existir éticamente" es la característica sobresaliente de la modernidad. Ello indica su falta de seriedad $(A l v o r)^{16}$ con respecto al "autoconocimiento" que la ética implica.

14 En el contexto de las Conferencias Kierkegaard parece identificar la "modernidad" con el pensamiento puro del "idealismo hegeliano". Según el danés, Hegel establece una identidad entre pensar y ser impidiendo con este procedimiento plantear adecuadamente el problema moral del sujeto existente o inter-esse, cuyos dilemas morales no se presentan en el plano del "conocimiento puro" sino en el devenir de la existencia que acaece "entre" el pensar y el ser.

${ }^{15}$ Papirer, VIII.2 B, 81, 5.

${ }^{16}$ Lo serio es que yo como individuo me relacione con Dios y de ese modo con cada ser humano. Es importante resaltar aquí que existe una relación de responsabilidad ética con los demás. Kierkegaard no es un solipsista. Lo que ocurre es que esa relación está mediada por Dios. La "seriedad" consiste en ayudar a un hombre a que él mismo se relacione con Dios. Esto debe hacerse indirectamente pues de lo contrario el maestro se transforma en un obstáculo para quien es ayudado. 
Kierkegaard hace uso de una diferencia epistemológica elemental: distingue el "conocimiento de algo" (Viden om Nogen) del "autoconocimiento" (Selverkiendelse) $)^{17}$, que en sentido estricto no puede pensarse como científico, pues no implica ningún "saber" en sentido tradicional. El primer tipo de conocimiento supone un objeto, es el conocimiento en todas sus formas, partiendo de la empiria hasta alcanzar las ciencias más abstractas. Por su parte, el autoconocimiento no hace referencia al "yo puro", conocido de modo fantástico, sino al "yo concreto" que cada individuo particular deviene en su existencia. Por este motivo, Kierkegaard contrapone la ética kantiana a la socrática. No obstante, reconoce que entre ambas media un acontecimiento histórico que presenta la mayor relevancia espiritual, pues supone la introducción de la noción de "eternidad" en la constitución de la conciencia humana. El yo frente a la eternidad deviene conciencia de lo eterno, que es uno de los modos de defínir lo ético, en contraposición a la inmediatez de la conciencia estética que desconoce la paradoja de la introducción de la eternidad en el tiempo, es decir, el paradigma del Dios-Hombre. La ética en Kierkegaard no tiene ningún valor si no es sobre la base de esta paradoja. Lo ético en las Conferencias es el "presupuesto" definitorio de la condición humana del mismo modo que el pecado es el presupuesto en El concepto de la angustia. "Lo ético" no comienza con la ignorancia que debe ser transformada en conocimiento sino con un conocimiento que exige realización.

La comunicación del fenómeno ético supone la abolición del sentido habitual de la comunicación que consta de cuatro elementos, a saber: el receptor, el emisor, el objeto y la comunicación. El objeto de la comunicación queda abolido pues "todos" lo conocemos. A su vez, el emisor no tiene nada que comunicar, y por lo tanto, el receptor también queda abolido. De este modo la comunicación no se realiza. Esta abolición permite, no obstante, la constitución de un nuevo concepto de comunicación que está basado en la distinción entre comunicar algo como arte y comunicarlo como ciencia. Al ser "previamente" conocido por todos, lo ético no puede ser comunicado de otra manera que no sea como arte. En este caso, el objeto de la

${ }^{17}$ Ctr. Papirer, VIII.2 B 81. 
comunicación no es un "conocimiento" sino una "realización". El maestro en la comunicación de un arte se convierte en tal o bien por la competencia o bien por la autoridad. Cuando hablamos de lo ético una persona no puede tener autoridad con relación a otra pues, éticamente, el maestro es Dios y todo hombre es un aprendiz. Tampoco la competencia puede producir un maestro en este terreno pues éticamente cada hombre se relaciona por sí mismo con Dios como un aprendiz y tiene como tarea su propio desarrollo.

La enseñanza de lo ético exige que el maestro se convierta en modelo de lo que predica. En este sentido, la figura de Cristo presenta un carácter ético, que sólo puede expresarse indirectamente. Una pregunta a responder es la siguiente: siendo que la seriedad es que el individuo se relacione con Dios y con los demás a través de él, si la ética es seriedad y la ironía la máxima seriedad, ¿debe concluirse que la comunicación de lo ético sólo puede realizarla propiamente el ironista? ${ }^{18}$

\section{4. Ética negativa vs. Reducción de la ética a la dogmática}

La mayoría de las aparentes similitudes que Conant y Ferreira encuentran entre el pensamiento del primer Wittgenstein $y$ Kierkegaard son meramente formales y no pueden plantearse más que en un terreno teórico superficial. Probablemente, la confusión haya surgido a raíz de la utilización del lenguaje kierkegaardiano realizada por Wittgenstein para describir el problema de los límites del lenguaje y su relación con lo ético. Sin embargo, la filosofía del primer Wittgenstein no presenta ningún rasgo proveniente de la tradición kierkegaardiana a pesar de que puedan plantearse analogias

\footnotetext{
${ }^{18}$ La respuesta que se desprende de Temory Temblor -cuando Abraham le responde a Isaac el interrogante sobre la res para el sacrificio- parece ser afirmativa. La contestación del patriarca se presenta bajo la forma de la "ironía" por dos razones. En primer lugar, ésta es un recurso que forma parte del método indirecto de comunicación. En segundo lugar, "lo ético" sólo puede presentarse de modo indirecto ya que hacerlo "directamente" implicaria convertirlo en "saber tradicional" y de este modo traicionar su especificidad práctica (la exigencia de "realización") cayendo en la "deshonestidad" de la ciencia moderna.
} 
formales entre conceptos claves tales como: paradoja, absurdo, sin sentido y discurso directo e indirecto. ${ }^{19}$

Establecer un diálogo entre Kierkegaard y Wittgenstein exige reconocer que cada pensador mantiene una postura diferente. Si bien ambos analizan la relación ética-lenguaje partiendo de la distinción epistemológica kantiana entre el mundo de la naturaleza y el de la libertad, los caminos que cada uno de ellos sigue luego son disímiles. En definitiva, el primer Wittgenstein no comparte con Kierkegaard más que una sola idea: la concepción general de la incomunicabilidad de lo ético. Sin embargo, la idea de discurso indirecto que maneja Kierkegaard no puede pensarse desde la misma perspectiva que la distinción entre decir y mostrar que plantea el pensador vienés. En primer lugar, porque parten de presupuestos distintos. Mientras en el caso de Kierkegaard lo que determina los limites del lenguaje es una categoría de la existencia, a saber, el pecado ${ }^{20}-y$ hace que su filosofia del lenguaje esté asi condicionada por determinaciones ético-religiosas - a tal punto que el mal uso del lenguaje sea visto como un pecado ${ }^{21}$-en el caso del primer Wittgenstein sucede lo contrario pues es la teoría pictóricorepresentativa del lenguaje, cuyo fundamento es lógico, la que condiciona la ética, volviéndola algo inexpresable. ${ }^{22}$ En segundo lugar, si bien Kierkegaard distingue la "comunicación de

19 En todo caso, estas analogías no constituyen evidencia suficiente para poder establecer lá-influencia de Kierkegaard no ya en la "forma" del pensamiento de Wittgenstein sino en su "contenido". Esto implica que, como lo demuestra la tesis de Victor Ort, estudiar la influencia de Kierkegaard en Wittgenstein debería restringirse al trabajo del segundo Wittgenstein. Entre otras cosas, porque si bien es sabido que Wittgenstein leyó el Postscriptum, no se ha podido determinar si lo hizo antes o después de escribir el Tractatus. Larry Victor ORT: Wittgenstein's Kierkegaardian Heritage, Dissertation, Michigan: Michigan State University 1997, UMI Microform, 1998.

${ }^{20}$ Para Kierkegaard el límite de la ética es la "conciencia del pecado". El pecado mismo no se puede pensar ni conocer. Cfr. Postscriptum, p. 585: “...El pecado no es ni enseñanza ni doctrina para pensadores." "Es una categoria de la existencia y simplemente no puede ser enseñada."

${ }^{21}$ Kierkegaard, Papirer, XI. 2 A 128.

${ }^{22}$ De ello se sigue que, más tarde, junto con el abandono de la teoria representativa del lenguaje, la ética pueda expresarse como un juego de lenguaje más entre otros posibles. 
conocimiento" de la "comunicación de capacidad", suponiendo que ésta última no posee propiamente un "objeto", no lo hace porque no exista un "algo" que decir - como pretende Conant- sino porque presupone que este algo - lo ético- es ya universalmente conocido por todos los hombres, ${ }^{23}$ puesto que es lo que los define como tales.

La imposibilidad de elaborar una "teoría ética" es expresada tanto por el "primer Wittgenstein", como consecuencia de su concepción "figurativa" del lenguaje, como por la exposición "dilemática", pero no conclusiva en sentido argumental, que realizan de la ética los pseudónimos hasta 1846. Los pseudónimos, en definitiva, plantean el problema de la diferencia existente entre la "primera ética" (basada en la metafisica), y la "segunda ética" (que parte del dogma del pecado original) pero no lo resuelven. En Las obras del amor Kierkegaard responde a los pseudónimos y al escepticismo del "primer Wittgenstein" ofreciendo un "ejemplo" de lo que podría considerarse "segunda ética". Sin embargo, la respuesta que da, como muestra en las Conferencias, sólo puede ser "indirecta" pues en sentido estricto la ética exige ser expresada en el medio de la Virkelighed (actualidad), en la acción responsable que sólo se muestra en la "propia existencia" y no en el medio de la "posibilidad"que es un medio no-ético. En definitiva, de la ética "no se puede hablar". Hacerlo es expresarse a-éticamente. La ética sólo puede expresarse indirectamente a través de "las obras del amor". Es decir, lo ético supone convertir en efectivamente real lo que se expresa discursivamente. Esta exigencia de lo ético en Kierkegaard trae como consecuencia que, si la ética se expresa de modo efectivo en la realidad del agente moral, entonces todo discurso acerca de esta realidad resulta, en el mejor de los casos, "trivial". Ahora bien, si sucede lo contrario, es decir, si lo ético se plantea sólo en el nivel de la idealidad del discurso pero no se efectiviza en la práctica, el resultado es la "hipocresia". Esto es lo que Kierkegaard expresa utilizando la distinción entre el "medio" de la mera "posibilidad" y el

${ }^{23}$ Cfr. Papirer, VIII 2 B 79, 81-89. 
medio de la "realidad efectiva o actualidad" en los Papirer VIII. 2 B y en el Postscriptum. ${ }^{24}$

Ni Kierkegaard ni Wittgenstein están interesados en elaborar una "teoría ética". No obstante, es necesario aclarar que, mientras para el primer Wittgenstein la ética trasciende el discurso proposicional significativo, y por lo tanto no puede ser aprehendida científicamente, Kierkegaard no rechaza esta última posibilidad. La ética puede pensarse cientificamente. Sin embargo, pretender que la elaboración de una teoria ética pueda tener "efectos educativos". es un error de la ciencia moderna. Aquí es importante tener en cuenta en qué sentido "lo ético" no puede comunicarse, pues Kierkegaard no niega, como muchos han creido, la legitimidad del pensamiento objetivo. Es decir, la actualidad de lo ético no es impensable y puede traducirse a la "posibilidad", que es el medio propio del pensamiento. Este proceder es legítimo, y desde esta perspectiva lo ético no sólo puede pensarse sino también comunicarse. Lo que el pensador danés busca es hallar el "modo" apropiado de realizar esta comunicación. "Lo ético" puede pensarse y comunicarse en tanto es "lo universal" que define a todo ser humano. Lo que no puede comunicarse es la forma que lo ético adquiere en cada caso individual pues la exigencia de orientar la existencia en torno a un fin que le otorgue continuidad a la misma, "la tarea", sólo puede ser descubierta por el existente "personalmente", dado que se basa en la noción de "interés", que es de carácter personal. La obra pseudónima de Kierkegaard intenta, justamente, hacer referencia al "interés" llamando la atención acerca de la seriedad de las categorias existenciales a las que se enfrenta el individuo particular, es decir, el inter-esse, (el hombre en tanto ser que existe "en medio de", entre el ser $y$ el pensar), a través del uso de distintas posibilidades existenciales que solamente el individuo particular puede decidir "actualizar" o "rechazar". Por este motivo, el discurso pseudónimo no tiene sentido conclusivo sino que es presentado bajo la forma de la alternativa en el medio de la "posibilidad" intelectual.

24 "En relación con la posibilidad, las palabras son el pathos más elevado; en relación con la actualidad, el pathos más elevado son las acciones" (Postscriptum, VII 338). 
En sentido estricto, Wittgenstein no hace más que presentar lo que podríamos denominar una "ética negativa", puesto que a pesar de reconocer el sentido absoluto que tiene la experiencia moral para la vida del hombre, su postura final al respecto es la del "silencio". Si bien las "razones" por las que Wittgenstein guarda silencio sobre el tema ético son "kierkegaardianas", en tanto y en cuanto la exigencia de la ética es la de la "actualización" o "realización" en la propia existencia y no la de la proclamación discursiva, esto no es evidencia suficiente ni para afirmar ni para negar ninguna "influencia" radical de Kierkegaard sobre Wittgenstein.

Por otra parte, mientras el primer Wittgenstein nos abandona en una suerte de nihilismo moral, Kierkegaard intenta expresar "indirectamente" el significado de lo ético, cuyo fundamento último es la dogmática, puesto que la comprensión de lo moral no es adquirida en sentido pleno hasta que no se incorpora la "conciencia" del pecado. ${ }^{25}$

El "cristianismo" (el dogma del pecado original) es el criterio fenomenológico regulador de la "conciencia" en la progresión que ésta realiza con el objeto de alcanzar el autoconocimiento. Lo que permite que la conciencia avance en distintas direcciones es el "objeto" al que se enfrenta como queda explicitado en Temor $y$ Temblor y La enfermedad mortal. Por eso, la vida estética es sinónimo de desesperación tanto como la ética. En definitiva, si el yo no se constituye de modo "transparente" ante Dios, cualquier forma de autoconciencia, sea de lo estético o de lo ético, se convierte en "desesperación". La "voluntad" juega un rol preponderante en la dialéctica de la constitución del yo pues "querer" la desesperación y no simplemente padecerla, es el único medio que permite superarla. Para poder transformar completamente su existencia el individuo

\footnotetext{
25 Papirer, X 1 A 360 : "La ética, o mejor dicho, "lo ético" es el momento crítico, y a partir de alli el movimiento es hacia lo dogmático." La conciencia plena de lo ético sólo se alcanza al reconocer el movimiento hacia la dogmática porque lo que está en juego es la salvación eterna.
} 
debe elegir la "desesperación", ya que de esta manera accede a una forma superior de existencia caracterizada por la "verdadera libertad" del yo histórico concreto que "elige" desesperar, aceptando de esta forma sostenerse en el poder eterno que lo fundamenta. 
Copyright of Tópicos. Revista de Filosofía is the property of Universidad Panamericana and its content may not be copied or emailed to multiple sites or posted to a listserv without the copyright holder's express written permission. However, users may print, download, or email articles for individual use. 